\title{
The Effect of Stochastically Varying Creep Parameters on Residual Stresses in Ceramic Matrix Composites
}

\author{
Evan J. Pineda \\ Glenn Research Center, Cleveland, Ohio \\ Subodh K. Mital \\ University of Toledo, Toledo, Ohio \\ Brett A. Bednarcyk and Steven M. Arnold \\ Glenn Research Center, Cleveland, Ohio
}




\section{NASA STI Program . . . in Profile}

Since its founding, NASA has been dedicated to the advancement of aeronautics and space science. The NASA Scientific and Technical Information (STI) Program plays a key part in helping NASA maintain this important role.

The NASA STI Program operates under the auspices of the Agency Chief Information Officer. It collects, organizes, provides for archiving, and disseminates NASA's STI. The NASA STI Program provides access to the NASA Technical Report Server-Registered (NTRS Reg) and NASA Technical Report ServerPublic (NTRS) thus providing one of the largest collections of aeronautical and space science STI in the world. Results are published in both non-NASA channels and by NASA in the NASA STI Report Series, which includes the following report types:

- TECHNICAL PUBLICATION. Reports of completed research or a major significant phase of research that present the results of NASA programs and include extensive data or theoretical analysis. Includes compilations of significant scientific and technical data and information deemed to be of continuing reference value. NASA counter-part of peer-reviewed formal professional papers, but has less stringent limitations on manuscript length and extent of graphic presentations.

- TECHNICAL MEMORANDUM. Scientific and technical findings that are preliminary or of specialized interest, e.g., "quick-release" reports, working papers, and bibliographies that contain minimal annotation. Does not contain extensive analysis.
- CONTRACTOR REPORT. Scientific and technical findings by NASA-sponsored contractors and grantees.

- CONFERENCE PUBLICATION. Collected papers from scientific and technical conferences, symposia, seminars, or other meetings sponsored or co-sponsored by NASA.

- SPECIAL PUBLICATION. Scientific, technical, or historical information from NASA programs, projects, and missions, often concerned with subjects having substantial public interest.

- TECHNICAL TRANSLATION. Englishlanguage translations of foreign scientific and technical material pertinent to NASA's mission.

For more information about the NASA STI program, see the following:

- Access the NASA STI program home page at http://www.sti.nasa.gov

- E-mail your question to help@sti.nasa.gov

- Fax your question to the NASA STI Information Desk at 757-864-6500

- Telephone the NASA STI Information Desk at 757-864-9658

- Write to:

NASA STI Program

Mail Stop 148

NASA Langley Research Center Hampton, VA 23681-2199 
NASA/TM-2015-218759

AIAA-2015-0389

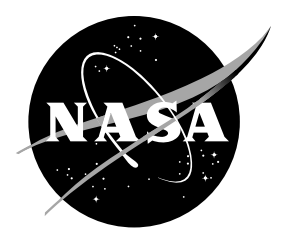

\title{
The Effect of Stochastically Varying Creep Parameters on Residual Stresses in Ceramic Matrix Composites
}

\author{
Evan J. Pineda \\ Glenn Research Center, Cleveland, Ohio \\ Subodh K. Mital \\ University of Toledo, Toledo, Ohio \\ Brett A. Bednarcyk and Steven M. Arnold \\ Glenn Research Center, Cleveland, Ohio
}

Prepared for the

SciTech 2015

sponsored by the American Institute of Aeronautics and Astronautics

Kissimmee, Florida, January 5-9, 2015

National Aeronautics and

Space Administration

Glenn Research Center

Cleveland, Ohio 44135 
Level of Review: This material has been technically reviewed by technical management.

Available from

NASA STI Program

Mail Stop 148

NASA Langley Research Center

Hampton, VA 23681-2199
National Technical Information Service 5285 Port Royal Road Springfield, VA 22161

$703-605-6000$

This report is available in electronic form at http://www.sti.nasa.gov/ and http://ntrs.nasa.gov/ 


\title{
The Effect of Stochastically Varying Creep Parameters on Residual Stresses in Ceramic Matrix Composites
}

\author{
Evan J. Pineda \\ National Aeronautics and Space Administration \\ Glenn Research Center \\ Cleveland, Ohio 44135 \\ Subodh K. Mital \\ University of Toledo \\ Toledo, Ohio 43606 \\ Brett A. Bednarcyk and Steven M. Arnold \\ National Aeronautics and Space Administration \\ Glenn Research Center \\ Cleveland, Ohio 44135
}

\begin{abstract}
Constituent properties, along with volume fraction, have a first order effect on the microscale fields within a composite material and influence the macroscopic response. Therefore, there is a need to assess the significance of stochastic variation in the constituent properties of composites at the higher scales. The effect of variability in the parameters controlling the time-dependent behavior, in a unidirectional SCS-6 SiC fiber-reinforced RBSN matrix composite lamina, on the residual stresses induced during processing is investigated numerically. The generalized method of cells micromechanics theory is utilized to model the ceramic matrix composite lamina using a repeating unit cell. The primary creep phases of the constituents are approximated using a Norton-Bailey, steady state, power law creep model. The effect of residual stresses on the proportional limit stress and strain to failure of the composite is demonstrated. Monte Carlo simulations were conducted using a normal distribution for the power law parameters and the resulting residual stress distributions were predicted.
\end{abstract}

\section{Introduction}

CERAMIC matrix composites (CMCs) provide excellent high-temperature capabilities with much lower mass $\checkmark$ compared to high-temperature superalloys. They are thus under development for aerospace applications such as entry, ascent, and cruise vehicles, leading edges, control surfaces, combustor liners, and gas turbine engine vanes and blades. Examples of three CMCs are shown in Figure 1. Woven melt infiltrated (MI) CMCs tend to have voids within the tows, but good matrix density between the tows. Woven chemical vapor infiltrated (CVI) CMCs have voids within the tows as well as large voids between the tows. With unidirectional and laminated MI CMCs, excellent matrix density can be achieved both within and between the tows with a simpler manufacturing. In all three types of $\mathrm{CMCs}$, the fiber filaments are coated, which provides a very compliant interface to inhibit matrix cracks from entering the fibers.

Variability in the stiffness, strength and proportional limit stress (PLS) of CMCs has been demonstrated to be significant, compared to polymer matrix composites (PMCs). ${ }^{1}$ The mismatch in stiffness between the fibers and matrix in CMCs tend to be far lower than that of PMCs. As such, the response of CMCs is not "fiber-dominated," and the performance of CMCs is highly sensitive to defects and imperfections arising from the manufacturing process. These imperfections can be architectural, including fiber volume fraction, variability in fiber diameter and coating thickness, fiber clustering, and voids. Moreover, the constituent properties may be non-uniform due to thermal gradients and microstructral variability (grain size, grain boundary phase, defects, etc) induced during processing. For instance, grain growth in the ceramic matrix is a key aspect resulting directly from thermal processing. Fine grains tend to creep more, but give higher strengths than coarse grains. So, there is a tradeoff between strength and creep resistance. The effects of all these imperfections can be taken into consideration by assuming variability in the effective material properties of the constituents. Finally, the presence of residual stresses (introduced during the manufacturing process) is highly influenced by the in-situ constituent properties, and also has a significant impact on the performance of CMC components. ${ }^{2-4}$ 
Multiscale modeling is a useful technique for capturing the effect of variability at one scale on the response at higher scales. Variability in the CMC microstructure and material parameters can be modeled directly using micromechancs and linked to the higher scales using hierarchical, concurrent, or synergistic "handshaking techniques". ${ }^{5}$ Since the constituents are modeled explicitly, residual stresses can be predicted by applying the appropriate processing history. Through multiscale modeling, combined with the flexibility available in the design of CMC materials afforded by the presence of three constituents, and the significance of residual stresses on performance, integrated computational materials engineering (ICME), which aims to tailor the material for a given purpose, is achievable. With concurrent and synergistic multiscale modeling, the fidelity of the micromechanics model can have adverse effects on the computational cost of the multiscale analysis. However, multiscale modeling has been achieved successfully using a variety of suitable analytical, semi-analytical, and numerical micromechanics models. ${ }^{6-9}$

The generalized method of cells (GMC) provides a semi-analytical solution for the local fields (stresses, elastic strains, thermal strains and inelastic strains) within a repeating unit cell (RUC) that is discretized into a number of subcells. ${ }^{9,10}$ Traction and displacement continuity conditions, along with periodic boundary conditions, are utilized with local constitutive laws to formulate a strain concentration matrix relating the globally applied strains to the local subcell strains. The generality of the method admits any linear or nonlinear, elastic or inelastic constitutive model. GMC has been utilized to capture the stochastic response of woven CMCs exhibiting damage, and the effect of residual stresses on performance. ${ }^{3,4,11}$ Furthermore, the semi-analytical formulation of GMC results in ultra-efficient computation making the method ideal for inclusion within a multiscale ICME framework. ${ }^{12-14}$ In addition, the use of GMC for stochastic multiscale analysis has been demonstrated. ${ }^{11,15-17}$

As stated previously, residual stresses (occurring during processing) can have a substantial influence on the performance of CMCs. The main driver for these residual stresses is the mismatch in thermo-elasticinelastic constituent properties. Thus, understanding the evolution of residual stresses is important for predicting performance. Although it is understood that variation in the elastic properties and coefficients of thermal expansion (CTEs) of the constituents will affect the residual stress state, the primary focus of this work is to investigate the effects of variability, and corresponding disparity, in the inelastic (creep) properties of the ceramic constituents on the post-manufactured residual stresses in CMCs. While variability in the fiber architecture is evident (see Figure 1) and it affects the residual stresses in the CMC, herein an ordered, square-packed RUC is utilized throughout; 1) for computational efficiency and 2) to isolate the effects of constituent property variation from variability in the microstructure. The influence of microstructural variability on the deformation and life of directional composites has been studied by others. ${ }^{18}$

For this study a demonstrative material system composed of continuous SCS-6 silicon carbide (SiC) fiberreinforced reaction bonded silicon nitride (RBSN) matrix with a boron nitride (BN) coating around the $\mathrm{SiC}$ fibers was chosen. ${ }^{19,20}$ Residual stresses arise in this material as a result of differences in the coefficients of thermal expansion (CTE) in the fibers and matrix. ${ }^{2}$ During processing the residual stresses redistribute (relax), due to the time-dependent behavior of the ceramic constituents (SiC fiber and RBSN matrix). ${ }^{20,21}$ For simplicity, the time-dependent behavior is modeled using power law creep in GMC. ${ }^{9,22,23}$ Thermal loads are applied to a single fiber RUC to simulate processing using the MAC/GMC micromechanics code, developed at the NASA Glenn Research Center (GRC). ${ }^{24,25}$ A normal distribution for each creep parameter is assumed and Monte Carlo simulations are performed to probe the effect of variability in the creep parameters ( $A$ and $n$ ) for each constituent (individually) on the residual stresses after manufacturing.

The effect of residual stresses on the performance (measured by changes in PLS and strain to failure $\epsilon_{f}$ ) of a CMC is demonstrated in Section II. The stochastic modeling approach used is described in detail in Section III. Finally, the predicted residual stress distributions are examined in Section IV and compared to a deterministic approach.

\section{Effect of Residual Stresses in Ceramic Matrix Composites}

Previous work has shown the effect of residual stresses on CMCs; that work is reviewed briefly in this section. ${ }^{4,26}$ A CMC RUC, shown in Figure 2 was modeled using GMC. Although, the previous study (summarized here) involved a SiC-SiC CMC, the novel work in this manuscript focuses on a SiC-RBSN CMC material due to the availability of material properties, and other information, in the open literature. The same observed relationship between residual stresses and the macroscopic composite response is applicable, regardless of the specific CMC system. The matrix subcells are represented in green, the fiber subcell in 
blue and the coating subcells in pink. The RUC was subjected to an idealized processing history, during which the time-dependent behavior of the fiber and matrix is approximated using a power law creep model, and the ensuing residual stresses are shown in Figure 3. The fundamental cause of the residual stresses is the discrepancy between the constituent properties. The magnitude of residual stresses developed is a result of stress redistribution induced by a disparity in the thermo-elastic properties (e.g. stiffness and CTEs). However, the rate and magnitude of redistribution between constituents is driven by differences in the creep properties of the constituents. Thus, the assumed creep properties and process history will significantly affect the final residual stress state.

After processing, the matrix is under a longitudinal compressive stress, and the fiber is subjected to a longitudinal tensile stress since the CTE of the fiber is greater than the CTE of the matrix in the longitudinal direction.A bilinear progressive damage model was employed for the matrix, a maximum stress failure criterion was used for the fiber, and the RUC was subjected to longitudinal tension after application of processing. The impact of the residual stresses on the tensile response of a CMC is shown in Figure 4. Residual compression in the matrix delays matrix cracking which leads to significant increase in the predicted "knee" in the stress strain curve (PLS increases). Conversely, residual longitudinal tension in the fiber yields a reduction in predicted strain to failure $\left(\epsilon_{f}\right)$ because of the pre-strain existing in the fiber after processing. Thus, there will always be a trade off between PLS and strain to failure. Matrix cracking can result in oxidation and other adverse environmental effects. Therefore, it may be desirable to process the CMC such that the $\epsilon_{f}$ is reduced in exchange for an increase in the PLS. So, if the PLS is used as a design criterion for the composite material, then clearly the compressive matrix residual stresses are very beneficial.

Figure 5 shows the predicted effect of heat treatment on the room temperature response the composite. Heat treatment at a moderate temperature $T_{3}$, even for a long duration $t_{1}$, only allows for a small reduction in the residual stress, and thus only changes the tensile response slightly. However, heat treatment at $T_{1}\left(T_{1}>T_{3}\right)$ for a shorter time $t_{2}\left(t_{2}=0.1 t_{1}\right)$ yields a substantial reduction in the residual stress, and consequently the composite tensile response is much closer to the predicted response with no residual stresses. Figure 5 demonstrates the competing effect of processing time and temperature on the post-manufactured residual stress state, and hence, performance of a CMC. Clearly, application at elevated temperature can eventually lead to a reduction of PLS. Then, given enough time and thermal driving force, matrix cracking will occur when the CMC is loaded beyond the PLS corresponding to zero residual stresses. This is similar to the concept of creep buckling.

Figure 6 shows the impact of heat treatment at $T_{1}$ for $t_{2}$ on the predicted longitudinal creep response of the composite at $T_{1}$. The applied stress level is $200 \mathrm{MPa}$, which is below the predicted PLS of the composite. The effect is noticeable, but not large (due to the higher creep resistance of the fiber compared to the matrix) because the composite does not creep very much in the longitudinal direction. Further heating up to $T_{2}$, prior to applying the simulated creep loading, eliminates some of the residual stresses.

Figures 4-6 show the importance of stress relaxation and processing on the residual stresses in, and ultimately the performance of, the composite. However, these results do not account for any statistical variation in the material properties or fiber-matrix architecture. These unaccounted for distributions may significantly affect the performance of the material. Understanding the influence of stochastic distributions at the microscale is critical for ICME.

\section{Stochastic Modeling Approach}

The previous section demonstrated the impact residual stresses can have on a CMC, supporting other work in the literature. ${ }^{2,3}$ However, the focus of this work is to examine the effect of variability in the creep parameters of the CMC constituents on the residual stresses. Monte Carlo simulations utilizing GMC as the micromechanics theory were preformed on a unidirectional SiC-RBSN system using the MAC/GMC software package. The same processing history was used for each simulation, but the creep parameters for the SiC fiber and RBSN matrix were chosen randomly using a normal distributions.

\section{III.A. The Generalized Method of Cells}

With GMC, an RUC must be identified that represents the composite microstructure, and the RUC is discretized into a number of subcells. The RUC chosen to represent the unidirectional SiC-RBSN system is shown in Figure 7. The unidirectional lamina is composed of continuous reinforcement in the axial, $x_{1^{-}}$ 
direction. Thus, it is assumed that the RUC extends infinitely in that direction, and the RUC is subjected to a state of generalized plane strain; therefore, the doubly-periodic formulation of GMC is presented herein. Each subcell can be occupied by a single constituent (obeying the constitutive law of that constituent), but there is no limit on the number of different constituents that can be present in the RUC. Displacement and traction continuity is enforced in an average, or integral, sense at each of the subcell interfaces and the periodic boundaries of the RUC. These continuity conditions are used to formulate elastic and inelastic strain concentration matrices $\mathbf{A}$ and $\mathbf{D}$, respectively.

$$
\boldsymbol{\epsilon}_{S}=\mathbf{A} \overline{\boldsymbol{\epsilon}}+\mathbf{D}\left(\boldsymbol{\epsilon}_{S}^{I}+\boldsymbol{\epsilon}_{S}^{T}\right)
$$

which gives all the local generalized Hookean subcell strains $\boldsymbol{\epsilon}_{\boldsymbol{S}}$ in terms of the six, global, average, applied strains $\overline{\boldsymbol{\epsilon}}$ and the local inelastic and thermal strains $\boldsymbol{\epsilon}_{S}^{I}$ and $\boldsymbol{\epsilon}_{S}^{T}$. Note that, even though the formulation is doubly-periodic the stress and strain fields are fully-3D both globally and locally.

Once the strain concentration matrix is formulated and the local subcell strains have been calculated, the local subcell stresses $\boldsymbol{\sigma}^{(\beta \gamma)}$ can be calculated using the local constitutive law and the local subcell strains.

$$
\boldsymbol{\sigma}^{(\beta \gamma)}=\mathbf{C}^{(\beta \gamma)}\left(\boldsymbol{\epsilon}^{(\beta \gamma)}-\boldsymbol{\epsilon}^{\boldsymbol{I}^{(\beta \gamma)}}-\boldsymbol{\epsilon}^{\boldsymbol{T}^{(\beta \gamma)}}\right)
$$

where $\beta$, and $\gamma$ are the subcell indices in the $x_{2^{-}}$, and $x_{3^{-}}$-directions, respectively, $\mathbf{C}^{(\beta \gamma)}$ is the local subcell stiffness, $\boldsymbol{\epsilon}^{(\beta \gamma)}$ contains the six local subcell strains, $\boldsymbol{\epsilon}^{I^{(\beta \gamma)}}$ are the inelastic strains, and $\boldsymbol{\epsilon}^{T(\beta \gamma)}$ are the thermal strains. Finally, the global RUC (composite) stiffness can be calculated.

$$
\mathbf{B}=\frac{1}{H L} \sum_{\beta=1}^{N_{\beta}} \sum_{\gamma=1}^{N_{\gamma}} h_{\beta} l_{\gamma} \mathbf{C}^{(\beta \gamma)} \mathbf{A}^{(\beta \gamma)}
$$

where $N_{\beta}$, and $N_{\gamma}$ are the total number of subcells in the $x_{2^{-}}$, and $x_{3}$-directions, respectively, $H$, and $L$ are the RUC dimensions in the $x_{2^{-}}$, and $x_{3}$-directions, $h_{\beta}$, and $l_{\gamma}$ are the local subcell dimensions in the $x_{2^{-}}$, and $x_{3}$-directions for subcell $\beta \gamma$, and $\mathbf{A}^{(\beta \gamma)}$ is a submatrix of the strain concentration matrix $\mathbf{A}$ corresponding to subcell $\beta \gamma$.

Table 1 contains the volume fractions $(V)$ for each constituent used in all analyses. The SiC fiber volume fraction $V^{f}$ was $30 \%$, the RBSN matrix volume fraction $V^{m}$ was $62 \%$ and the BN coating volume fraction $V^{c}$ was $8 \%$. The elastic properties and CTEs, at room temperature, for the SiC fiber, RBSN matrix, and $\mathrm{BN}$ coating used in all simulations are also presented in Table 1, where $E$ indicates Young's modulus, $\nu$ indicates Poisson's ratio, and $\alpha$ indicates CTE. The elastic properties of all three materials are isotropic but the longitudinal and transverse CTEs for the $\mathrm{SiC}$ fiber are different and are designated with a subscript $L$ and $T$, respectively. The Young's modulus and CTEs of the fiber and matrix are also temperature dependent. The values of these parameters at specific temperatures are given in Table 2 with linear interpolation being applied to arrive at intermediate temperatures. In Table 2, $\mathrm{SiC}$ fiber properties are marked with a superscript $f$, RBSN matrix properties are marked with a superscript $m$.

\section{III.B. Stochastic Modeling of Time- and Temperature-Dependent Response}

The aim of this work is to investigate the effect of variability in the time-dependent deformation, during processing, on the resulting residual stresses in the SiC-RBSN CMC. To achieve this, the inelastic strain rate components $\dot{\epsilon}_{i j}^{(\beta \gamma)}$ are related to the second stress invariant $J_{2}^{(\beta \gamma)}$ and components of the deviatoric stress tensor $s_{i j}^{(\beta \gamma)}=\sigma_{i j}^{(\beta \gamma)}-\delta_{i j} \sigma_{k k}^{(\beta \gamma)} / 3$ (where $\delta_{i j}$ is the Kronecker delta) in each subcell through a Norton-Bailey power law creep relation. ${ }^{9}$

$$
\dot{\epsilon}_{i j}^{(\beta \gamma)}=\frac{3}{2} \tilde{A}(T)\left(3 J_{2}^{(\beta \gamma)}\right)^{\frac{n-1}{2}} s_{i j}^{(\beta \gamma)}
$$

where $n$ is the power law exponent, and $\tilde{A}(T)$ is a temperature dependent material constant (scaling factor) related to the activation energy for the material, $Q$, and the ideal gas constant, $R$.

$$
\tilde{A}(T)=A \exp \left(-\frac{Q}{R T}\right)
$$


Under uniaxial loading, Eq. (4) simplifies to

$$
\dot{\epsilon}^{I^{(\beta \gamma)}}=\tilde{A}(T) \sigma^{(\beta \gamma)^{n}}
$$

Although the constituent materials often times exhibit a primary creep regime (i.e., a zone in which the inelastic strain rate decreases with increasing time), in this study a simple steady state creep model will be used. The influence of higher creep rates associated with the primary creep will be accounted for by characterizing the material parameters $A$ and $n$ using the concept of secant inelastic strain rate.

The strain versus time profile for primary stage, tensile creep of SCS-6 SiC fibers has been characterized previously. ${ }^{27}$

$$
\epsilon^{I}=A_{0} \sigma^{m} t^{p} \exp \left(-\frac{B}{T}\right)
$$

where $t$ is time and $A_{0}, m, p$ and $B$ are material parameters, given in Table 3 at an applied uniaxial stress of $500 \mathrm{MPa} .{ }^{27}$ Taking the time derivative of Eq. (7) yields an expression for the inelastic strain rate of an SCS-6 SiC fiber as a function of time under a uniaxial stress.

$$
\dot{\epsilon}^{I}=p A_{0} \sigma^{m} t^{p-1} \exp \left(-\frac{B}{T}\right)
$$

In order to obtain the parameters used in the steady state power law approximation of the primary creep regime of the SCS-6 SiC fibers, Eq. (6) is equated to the average creep strain rate $\dot{\bar{\epsilon}}^{I}$ during processing. This is obtained by time averaging Eq. (8) over a given processing time $t_{f}$ (herein taken to be the total time).

$$
\begin{gathered}
\dot{\bar{\epsilon}}^{I}=\int_{0}^{t_{f}} \dot{\epsilon}^{I} d t \\
\dot{\bar{\epsilon}}^{I}=A_{0} \sigma^{m} t_{f}^{p-1} \exp \left(-\frac{B}{T}\right)
\end{gathered}
$$

Assuming a uniaxial stress state $\left(\sigma_{11}^{(\beta \gamma)}=\sigma=500 M P a\right)$ and setting Eq. (6) equal to Eq. 10) yields expressions for the steady state creep approximation constants in terms of the creep strain profile constants.

$$
\begin{gathered}
\tilde{A}(T)=A_{0} t_{f}^{p-1} \exp \left(-\frac{B}{T}\right) \\
n=m
\end{gathered}
$$

Table 4 contains tabulated values of $\tilde{A}$ at critical processing temperatures. Figure 8 shows a comparison between the primary creep strain, given by Eq. (7), and the steady state secant approximation, calculated using a constant inelastic strain rate given by Eq. (6) with the values in Table 4, under a uniaxial stress of $500 \mathrm{MPa}$ over the duration of the processing at different critical processing temperatures. Clearly, this averaging procedure resulted in the steady state creep approximation achieving the same final inelastic strain as the primary creep equation at the end of processing, $t_{f}$.

The creep behavior of RBSN is not as well characterized as the SCS SiC fiber. Furthermore, it is difficult to measure the in situ matrix properties from experiments on bulk RBSN because the ceramic microstructures (grain size, grain boundary phases, defects, void content, etc.) are not the same. Thus, the creep properties of the RBSN matrix were adjusted such that the reduction in residual stresses (when compared to thermoelastic analysis) in the fiber, and matrix, upon completion of the thermal processing is discernible. Since the interest of this work is to investigate the effect of variability in creep properties on the residual stresses in the material, not to predict the performance of the CMC, the method used to approximate the creep parameters of the RBSN matrix is reasonable. The final values employed are presented in Table 4. Note that, it is assumed that the BN fiber coating does not exhibit any creep.

The RUC is subjected to the thermal process history given in Figure 9. The exact details of the thermal process history of this material are export controlled; thus, an idealized processing is given in Figure 9. The processing starts at $T_{1}$ and is held until time $t_{1}$, after which the temperature is ramped down to $T_{3}$ at $t_{2}$. An isothermal hold is performed at $T_{3}$ until $t_{3}$ is reached; whereupon the temperature is again ramped down to room temperature $\left(20^{\circ} \mathrm{C}\right)$. The total processing time is $t_{f}$. The resulting residual stresses, and subsequent material performance, obviously heavily rely on the process history. However, to isolate the effect of material 
property variation, the specific process history is held fixed (dictated by Figure 9). Although not done here, additional simulations could be performed to examine fluctuations or uncertainty in the process history on residual stresses.

Variability is introduced into each creep parameter by assuming a normal distribution with a standard deviation $(\sigma)$ equal to $10 \%$ of the mean $(\mu)$ values (given in Table 4 ). The stochastic value of the parameter $X$ is determined using

$$
X=\sigma \sqrt{-2 \ln r_{1}} \sin \left(2 \pi r_{2}\right)+\mu
$$

where $r_{1}$ and $r_{2}$ are random numbers. The probability density functions (PDF) for each creep parameter of each constituent $\left(\tilde{A}^{f}, \tilde{A}^{m}, n^{f}\right.$ and $\left.n^{m}\right)$ are displayed in Figures 10-11. The PDFs for $\tilde{A}$ are given for critical processing temperatures (shown in Figure 9). Although the mean values of $\tilde{A}$ are a function of temperature, the random numbers $r_{1}$ and $r_{2}$ used to determine the stochastic value of $\tilde{A}$ are fixed for each temperature during a single analysis. It is assumed that $n$ is independent of temperature.

To investigate the effect of variability in the creep parameters on the post-manufactured residual stress state, the Monte Carlo method is utilized. Multiple simulations are performed, and the creep parameter of interest is varied using Eq. (13) with different random values for $r_{1}$ and $r_{2}$ during each simulation. Consequently, each simulation performed has a different disparity in the inelastic (creep) properties among the constituents. However, for each simulation it is assumed that the creep properties of each material are spatially uniform; i.e. there is no variation in the creep parameters among the different subcells within the RUC that are occupied by the same constituent material. The RUC represents a material point in a larger continuum domain; thus, it is assumed that spatial variability occurs at the higher length scales than that represented with the RUC. To model spatial variability of creep parameters at the microscale would require the utilization of a statistical representative volume element (RVE), which inherently includes numerous fibers. ${ }^{9,17,28}$

\section{Results}

\section{IV.A. Residual Stresses in CMC Using a Deterministic Approach}

To observe the effect stress redistribution has on the residual stresses (which affect performance) in a SiCRBSN lamina, the SiC-RBSN RUC (see Figure 7) is subjected to the thermal profile given in Figure 9. First, it was assumed there was no time-dependent behavior in the constituents (wherein dwell periods within process histories would make no difference), and then the time-dependent response was modeled using the mean power law creep parameters from Table 4. The predicted, full-field, axial residual stress contours for these two cases are shown in Figure 12 at the end of processing, and the maximum and minimum residual stresses in the composite are given as a function of time in Figure 13.

Figure 12 shows that, subsequent to thermal processing, the axial residual stresses in the fiber are tensile and compressive in the matrix. This is consistent with experimental observations and it is deemed to improve the PLS of the composite provided the stresses in the fiber and matrix do not exceed the relative strengths in tension and compression, respectively. ${ }^{2}$ Comparing the longitudinal residual stresses in the fiber indicates that there is a $15.5 \%$ reduction in tensile stress from $437.4 \mathrm{MPa}$ to $369.5 \mathrm{MPa}$ if the stresses are allowed to relax using the parameters in Table 4 . Meanwhile, the compressive axial residual stresses in the matrix are similarly reduced by $15.5 \%$ from $-212.0 \mathrm{MPa}$ to $-179.0 \mathrm{MPa}$ when reduction in the residual stresses is enabled due to the accumulation of inelastic strain.

The predicted longitudinal residual stress history in each constituent is displayed in Figure 13. It can be seen that from the outset $t_{1}$ to $t_{2}$, stress relaxation enables some moderate reduction in the residual stresses, when compared to the residual stress accumulation in the purely thermo-elastic example. Although the majority of the residual stress and residual stress relaxation develops during the final cooldown from $t_{3}$ to $t_{f}$, as expected. To validate these residual stress predictions, a comparison with sophisticated multiscale experimental techniques would be required. ${ }^{29}$

As stated previously, the driving forces for the accumulation of residual stresses is the discrepancy of the thermo-elastic properties $(E$ and $\alpha$ ) between the constituents and the total change in temperature during processing. Conversely, the major driving forces enabling the development of inelastic strain, which effectively reduces the residual stresses, is the difference in the creep properties among the constituents, temperature and

time. Therefore, the final residual stress state is predicated upon a competition between the advancement of residual stresses due to constraints enacted by the difference in thermal expansion between the constituents, 
and the "relaxation" of those stress through time and temperature-dependent, inelastic dissipation. As such, the residual stresses in the post-manufactured material can be tailored through changes in the thermomechanical properties (elastic and inelastic) and applied process history.

It should be noted that, the term "stress relaxation" is used loosely to describe the reduction in residual stresses due to time-dependent development of inelastic strain. In fact, the mechanics of the thermal processing of a CMC are far more complex than isothermal stress relaxation or creep. Inelastic strain is developing within the constituents while the stresses are evolving, and yet the development of inelastic strain affects the stress evolution. Furthermore, the response is transversely isotropic. So, longitudinally the behavior might be closer to stress relaxation at a constant strain, but transversely the response may be more similar to creep at a fixed stress.

\section{IV.B. Effect of Variability in Creep Parameters on Residual Stresses}

The sensitivity of the inelastic strain rate $\dot{\epsilon}^{I^{(\beta \gamma)}}$ to changes in the material parameters $\tilde{A}$ and $n$ can be obtained by taking the partial derivative of Eq. (6) with respect to each parameter. As such, the sensitivity of the inelastic strain rate to changes in $\tilde{A}$ is

$$
\frac{\partial \dot{\epsilon}^{I^{(\beta \gamma)}}}{\partial \tilde{A}}=\sigma^{(\beta \gamma)^{n}}
$$

which is constant for a given stress, and $n$, and is independent of $\tilde{A}$. However, the sensitivity of $\dot{\epsilon}^{I^{(\beta \gamma)}}$ to changes in $n$ is a nonlinear function of $n$

$$
\frac{\partial \dot{\epsilon}^{(\beta \gamma)}}{\partial n}=n \tilde{A} \sigma^{(\beta \gamma)^{n-1}}
$$

for a given $\tilde{A}$ and $\sigma^{(\beta \gamma)}$

To determine the effect of variability in the creep properties of the constituents on the post-processed residual stresses, the Monte Carlo methodology, described in Section III.B was employed. The effect of variability in each of the four power law properties ( $\tilde{A}$ for the fiber and matrix, and $n$ for the fiber and matrix) was studied independently. Clearly in reality, some interdependence of these parameters would be expected - the investigation of correlation effects will be reserved for a future study. One thousand MAC/GMC simulations were conducted studying the effect of variability in each of the four creep parameters separately. The analyses were performed on a desktop workstation using a single Intel Xeon E5649 processor at $2.53 \mathrm{GHz}$ and with $24 \mathrm{~GB}$ of RAM. The average runtime for each of the four Monte Carlo simulation (which included 1000 serial analyses) was 436.4 seconds. Figures $14-17$ show the resulting variability in the post-processed, longitudinal residual stresses in the fiber and matrix of the unidirectional SiC-RBSN RUC.

Figure 14 shows histograms for the variability in the residual longitudinal tensile stress in the fiber, and compressive stress in the matrix, assuming a normal distribution in $\tilde{A}^{m}$ (see Eq. (4)) in the SCS-6 fiber with a standard deviation of $10 \%$ of the mean. The histograms were fit with PDFs assuming normal distributions for the residual stresses in the fiber and matrix. The mean tensile fiber and compressive matrix residual stresses were predicted to be $369.5 \mathrm{MPa}$ and $179.0 \mathrm{MPa}$, respectively. The corresponding standard deviations were predicted to be $0.43 \mathrm{MPa}(0.1 \%$ of the mean) and $0.21 \mathrm{MPa}(0.1 \%$ of the mean) in the fiber and matrix, respectively.

The residual stress histograms obtained by varying $\tilde{A}^{f}$ of the RBSN matrix are exhibited in Figure 15. The normal PDFs for these distributions predicted similar mean fiber tensile (369.8 MPa) and matrix compressive $(179.2 \mathrm{MPa})$ as the case when $\tilde{A}^{m}$ of the fiber was varied. However, the predicted standard deviations are $4.34 \mathrm{MPa}$ ( $1 \%$ of the mean) and $2.13 \mathrm{MPa}$ (1\% of the mean) for the fiber and matrix.

It was expected that imposing normal distribution on both $\tilde{A}^{f}$ and $\tilde{A}^{m}$ would result in a normal distribution of the resulting residual stresses because the sensitivity of the inelastic strain rate to changes in $\tilde{A}$ (in the fiber or matrix) is constant as given in Eq. (14). Moreover, the magnitude of $\tilde{A}$ does not affect the sensitivity of $\dot{\epsilon}^{(\beta \gamma)}$ to changes in $\tilde{A}$. The small standard deviations in the predicted residual stresses, shown in Figures 14 and 15, further support that variability in $\tilde{A}$ (for the fiber or matrix) is inconsequential.

Utilizing a normal distribution for the parameter $n^{f}$ in the SCS-6 SiC fiber resulted in a distribution of residual stresses for both fiber and matrix represented by the histograms in Figure 16. Note that, although a symmetric, normal distribution was used for $n^{f}$, the resulting residual stress distributions were not normal. 
A Weibull PDF best fit the residual stress data. This discrepancy between the distribution imposed on the input and the resulting distribution of the output was expected due to the non-linear sensitivity of the inelastic strain rate to changes in $n$, given by Eq. (15). Similar discrepancies between the shape of the distribution used to control the input parameters and the shape of the resulting output distribution have also been observed with respect to void distributions and damage. ${ }^{11}$ The mean residual tensile stress in the fiber was $368.9 \mathrm{MPa}$ with a standard deviation of $2.34 \mathrm{MPa}(0.6 \%$ of the mean), and the mean residual compressive stresses in the matrix $178.7 \mathrm{MPa}$ with a standard deviation of $1.16 \mathrm{MPa}$ ( $0.6 \%$ o f the mean).

Finally, Figure 17 shows the histogram for the residual stress distributions when $n^{m}$ for the RBSN matrix was varied. Again a normal distribution of $n^{m}$ did not result in a normal distribution of the predicted residual stresses. A generalized extreme value (GEV) PDF was used to fit the data. Variability in this paramter yielded a slight reduction in the mean residual stresses: $354.4 \mathrm{MPa}$ (tensile stress in fiber) and $171.8 \mathrm{MPa}$ (compressive stress in the fiber). Furthermore, the range of the variability in residual stresses was much larger as indicated by the standard deviations: $58.1 \mathrm{MPa}$ (16\% of the mean) for the tensile residual stresses in the fiber and $28.0 \mathrm{MPa}$ ( $16 \%$ of the mean) for the compressive residual stresses in the matrix. The effect of variability of $n^{m}$ was markedly more significant than $n^{f}$ because the mean value of $n^{m}$ was 3 as opposed to 1.1 for $n^{f}$. If Eq. (15) is evaluated with $n=n^{f}=1.1$, then the sensitivity of the inelastic strain rate with respect to changes in $n^{f}$ is on the order of $\propto \sigma^{(\beta \gamma)^{0.1}}$ Whereas, if Eq. (15) is evaluated at $n=n^{m}=3$, then the sensitivity of $\dot{\epsilon}^{I^{(\beta \gamma)}}$ with respect to changes in $n^{m}$ is on the order of $\propto \sigma^{(\beta \gamma)^{2}}$. Thus, it is clear that the standard deviation of residual stresses is a product of the sensitivity of the inelastic strain rate to changes in $n$ with respect to a particular mean.

Figures $14-17$ show the influence in the variability of the creep properties of the constituents on the predicted residual stresses in the CMC. Variation in the power law properties for the SCS-6 SiC fiber did not yield any major variability in the residual stresses. However, variation of the exponent $n^{f}$ produced a wider distribution in the residual stresses. The impact of variation in the RBSN matrix parameters was more significant. Using a normal distribution on $\tilde{A}^{m}$ for the matrix results in standard deviations an order of magnitude larger than those obtained by varying $\tilde{A}^{f}$ for the fiber. However, these standard deviations still remained within $1 \%$ of the mean. By far, the most influential parameter was $n^{m}$ of the RBSN matrix which exhibited standard deviations for the residual stress distributions in the fiber and matrix greater than $16 \%$ of he mean. Moreover, the resulting PDFs were not symmetric. The bias shown in the PDF indicates that there is a higher probability that variation in the power exponent $n^{m}$ of the RBSN matrix would yield a reduction in the residual stresses, rather than an increase. This study did not take into account variability in the distribution of fibers within the RUC because the focus was on material property variation, but it is expected that geometrical variability would also have marked effect on the resulting residual stresses.

\section{Conclusions}

The influence of variability in the material parameters controlling the time dependent response of the constituents in a SCS-6 SiC fiber-reinforced RBSN matrix unidirectional composite on the residual stresses induced during processing was demonstrated. The residual stress state is of particular importance for CMCs because it influences the performance (PLS and strain to failure) of the composite. ${ }^{2-4}$

In order to predict the evolution of residual stresses reasonably, micromechanics or multiscale modeling must be utilized. GMC, implemented within the MAC/GMC suite of micromechanics codes, was chosen as the modeling platform for all analyses. The time-dependent behavior of the SCS-6 SiC fiber and RBSN matrix, during processing, was approximated using power law creep. It was shown that time-dependent behavior in the fiber and matrix yields a redistribution of stresses in the constituents during processing.

Four sets of Monte Carlo simulations were conducted, varying each of the power law creep properties individually according to normal distributions. One thousand analyses were conducted for each Monte Carlo simulation and the average computational time for each Monte Carlo simulation was 436.4 seconds. The results of this study indicated that the creep exponent of the RBSN matrix had the largest effect on variability in the residual stresses within the processed composite. This was to be expected because of the relatively large mean value that was used and from a preliminary sensitivity analysis. Moreover, the sensitivity analysis revealed a constant sensitivity of the creep strain rate on changes in the power law scaling factor $A$, but a nonlinear dependence on the power law exponent. This was supported by the resulting shapes of the predicted residual distributions. The residual stress distribution takes the same form as the distribution used to introduce variability into the scaling factor $A$. However, if there is variability in the power law 
exponent, the resulting shape of the residual stress distributions cannot be inferred.

To achieve ICME, processing and performance must be linked in a fully coupled manner. This exercise has shown that processing effects, including variability, can be predicted for CMCs. If the impact of manufacturing on the creep parameters could be quantified then the resulting effects on residual stresses, and subsequently performance, could be estimated. Furthermore, if manufacturing affects only the power law constant $A$ (intercept of creep rate versus stress), then deterministic approaches could be utilized with more confidence because any statistical distribution of this parameter coincide with a similarly shaped distribution of the residual stresses. Yet, if manufacturing significantly affects the uncertainty of the creep exponent $n$ (slope of creep rate versus stress), a stochastic study is warranted. Although the present investigation did not account for microstructure variability, MAC/GMC is an ideal numerical tool for studying these effects in conjunction with material property variation. ${ }^{18,30}$ Furthermore, it has been demonstrated that, due to the computational efficiency of MAC/GMC, it is a viable software package for conducting statistical analyses and integration into an ICME framework. Future work will look at the effects of processing of laminates and will also include statistical modeling of thermo-elastic properties in conjunction with the creep properties. 


\begin{tabular}{|l|r|r|r|r|}
\hline Material & $V(\%)$ & $E(\mathrm{GPa})$ & $\nu$ & $\alpha_{L} / \alpha_{T}\left({ }^{\circ} \mathrm{C}^{-1}\right)$ \\
\hline \hline SiC Fiber & 30 & 390 & 0.17 & $4.1 \mathrm{E}-6 / 1.84 \mathrm{E}-6$ \\
\hline RBSN Matrix & 62 & 110 & 0.22 & $2.2 \mathrm{E}-6$ \\
\hline BN Coating & 8 & 1.8 & 0.22 & $2.0 \mathrm{E}-6$ \\
\hline
\end{tabular}

Table 1: Elastic properties and CTE for SiC-RBSN constituents at room temperature.

\begin{tabular}{|c|r|r|r|r|}
\hline Temperature & $E^{f}(\mathrm{GPa})$ & $\alpha_{L}^{f} / \alpha_{T}^{f}\left({ }^{\circ} \mathrm{C}^{-1}\right)$ & $E^{m}(\mathrm{GPa})$ & $\alpha^{m}\left({ }^{\circ} \mathrm{C}^{-1}\right)$ \\
\hline \hline$T_{3}$ & 357.2 & $5.83 \mathrm{E}-6 / 2.62 \mathrm{E}-6$ & 100.7 & $3.13 \mathrm{E}-6$ \\
\hline$T_{2}$ & 354.1 & $5.99 \mathrm{E}-6 / 2.69 \mathrm{E}-6$ & 99.9 & $3.22 \mathrm{E}-6$ \\
\hline$T_{1}$ & 351.0 & $6.15 \mathrm{E}-6 / 2.76 \mathrm{E}-6$ & 99.0 & $3.30 \mathrm{E}-6$ \\
\hline
\end{tabular}

Table 2: Elastic properties and CTE for SiC fiber $(f)$ and RBSN matrix $(m)$ constituents as a function of temperature.

\begin{tabular}{|c|c|c|c|}
\hline$A_{0}\left(\mathrm{MPa}^{-m} \cdot \mathrm{s}^{-p}\right)$ & $m$ & $p$ & $B(\mathrm{~K})$ \\
\hline \hline 1,995 & 1.1 & 0.37 & 25,800 \\
\hline
\end{tabular}

Table 3: Parameters used to characterize primary creep strain of SCS-6 fiber. ${ }^{27}$ 


\begin{tabular}{|c|r|r|r|r|}
\hline Temperature & $\tilde{A}^{f}\left(\mathrm{MPa}^{-n^{f}}\right)$ & $n^{f}$ & $\tilde{A}^{m}\left(\mathrm{MPa}^{-n^{m}}\right)$ & $n^{m}$ \\
\hline \hline Room Temp & 0. & 1.1 & 0. & 3.0 \\
\hline$T_{3}$ & $9.37 \mathrm{E}-8$ & 1.1 & $3.41 \mathrm{E}-10$ & 3.0 \\
\hline$T_{2}$ & $3.34 \mathrm{E}-7$ & 1.1 & $2.35 \mathrm{E}-8$ & 3.0 \\
\hline$T_{1}$ & $1.12 \mathrm{E}-6$ & 1.1 & $9.48 \mathrm{E}-7$ & 3.0 \\
\hline
\end{tabular}

Table 4: Temperature dependent baseline (mean) Norton-Bailey power law creep parameters for SCS-6 SiC fiber $(f)$ and RBSN matrix $(m)$. 


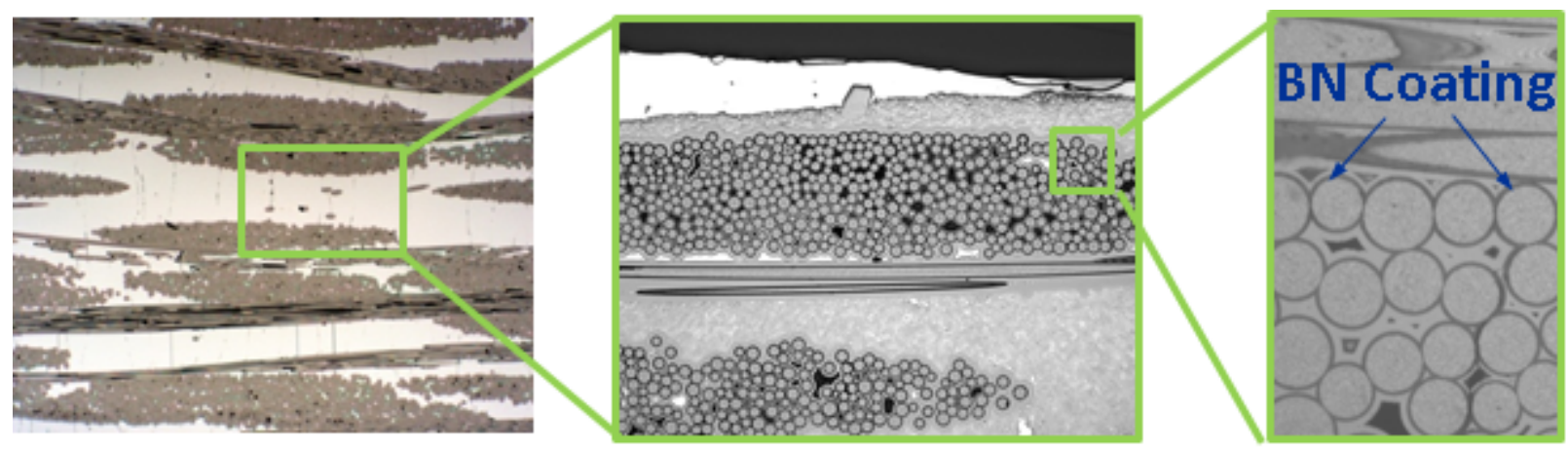

(a) Woven melt infiltrated (MI).

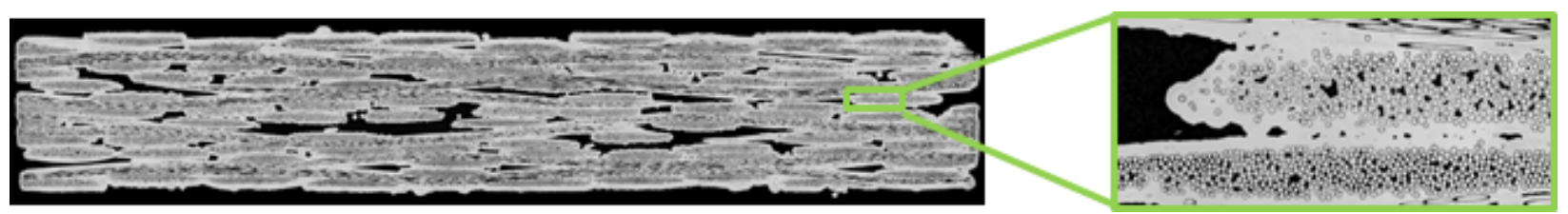

(b) Woven chemical vapor infiltration (CVI).
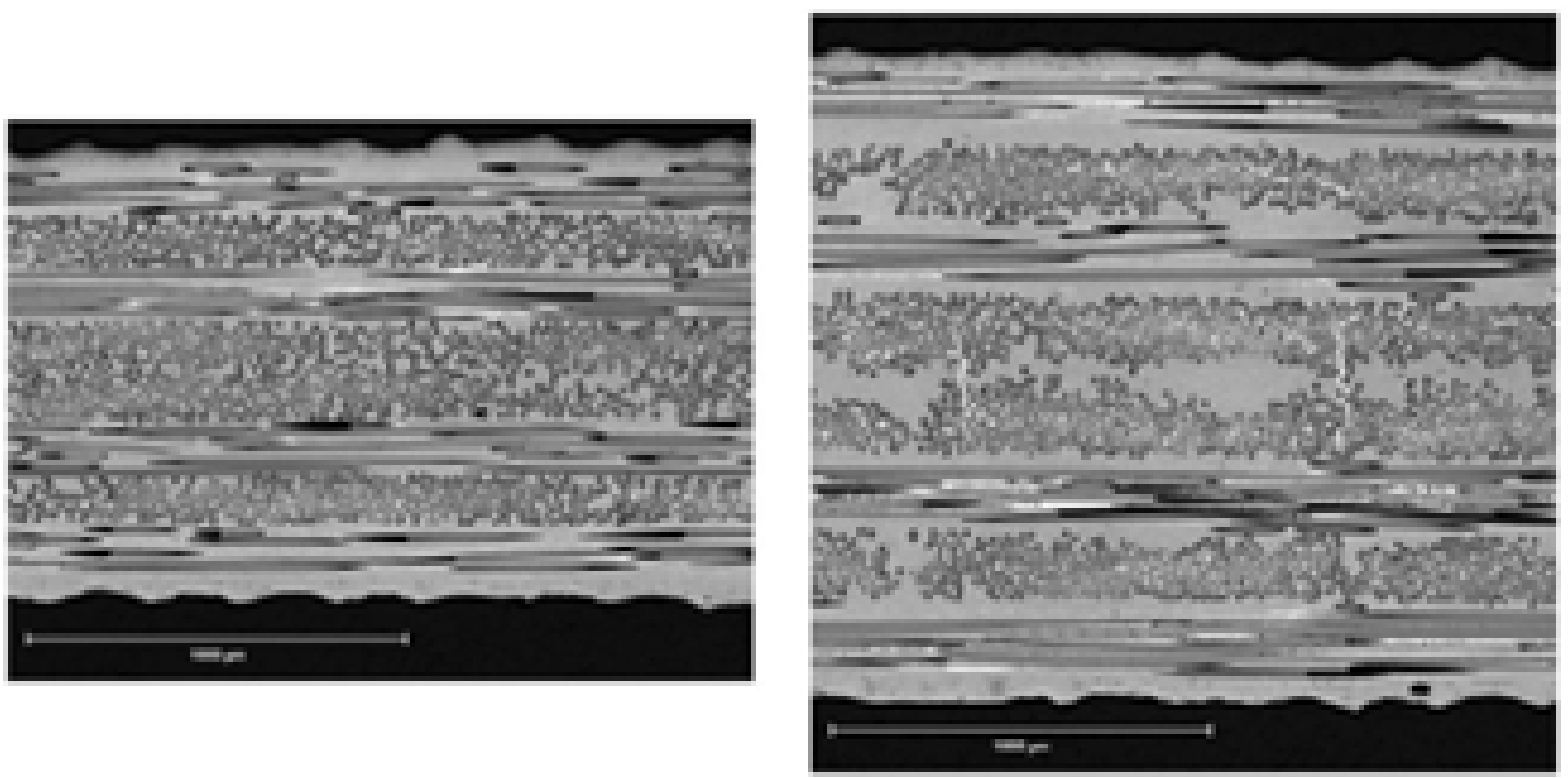

(c) Unidirectional or laminated MI.

Figure 1: Three types of ceramic matrix composites. 


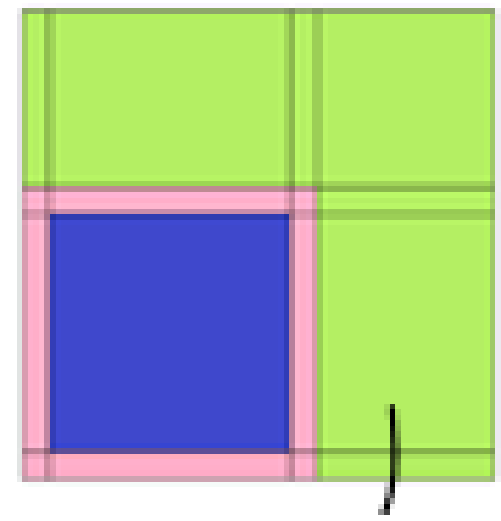

Figure 2: RUC used to model unidirectional CMC lamina. Matrix subcells are green, fiber subcell is blue, and coating subcell is pink.

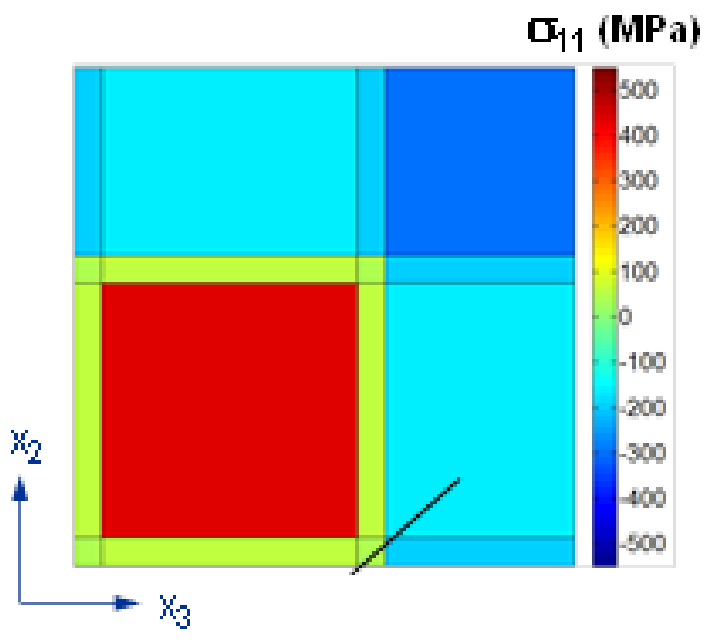

Figure 3: Predicted residual stresses in CMC RUC after being subjected to a thermal processing history.



Figure 4: Predicted room temperature longitudinal tensile response of the unidirectional CMC with and without residual stresses resulting from processing. 


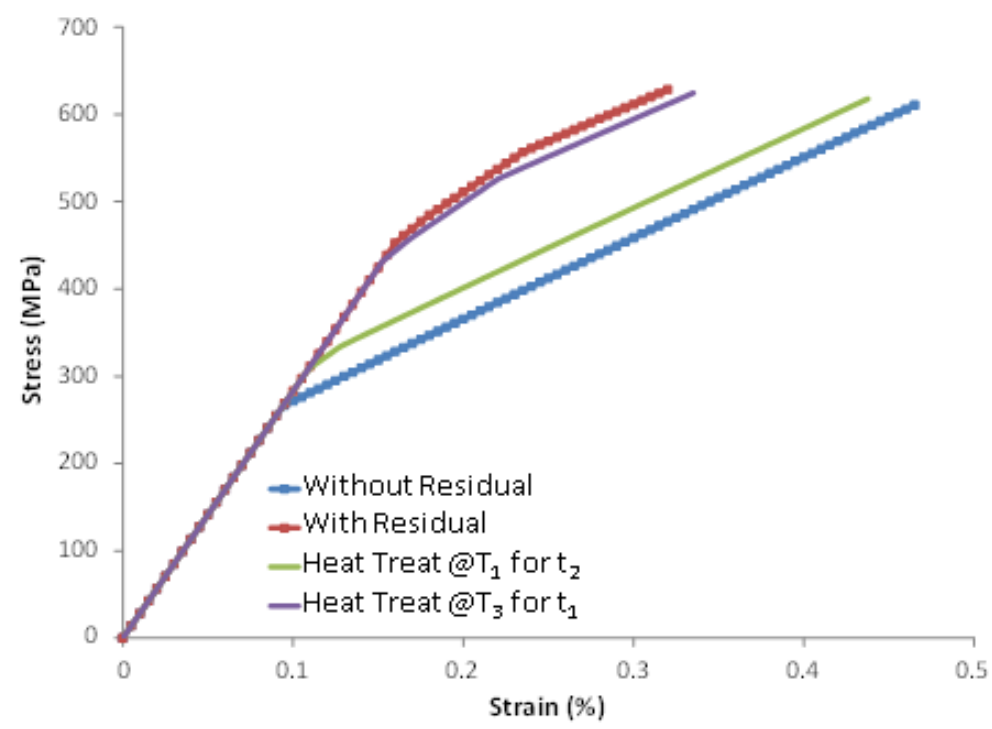

Figure 5: Predicted room temperature longitudinal tensile response of the unidirectional CMC after heat treatment at temperatures $T_{1}>T_{3}$ for times $t_{2}=t_{1} / 10$.

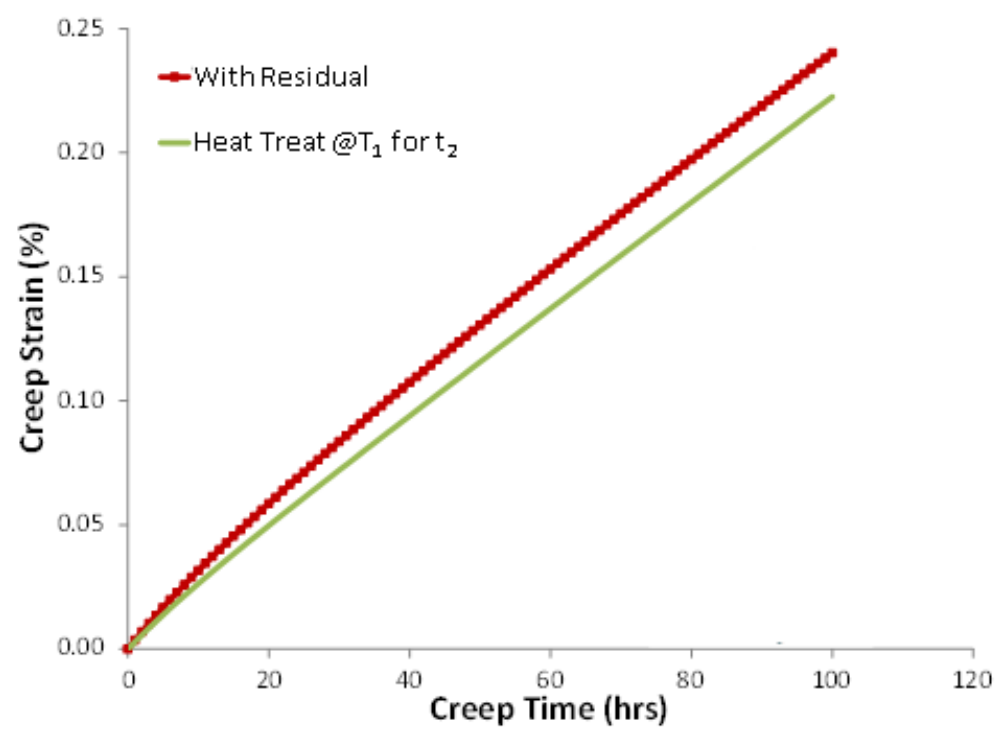

Figure 6: Predicted longitudinal creep response of the unidirectional CMC at $T_{1}$ with and without heat treatment, in response to an applied stress of $200 \mathrm{MPa}$. 


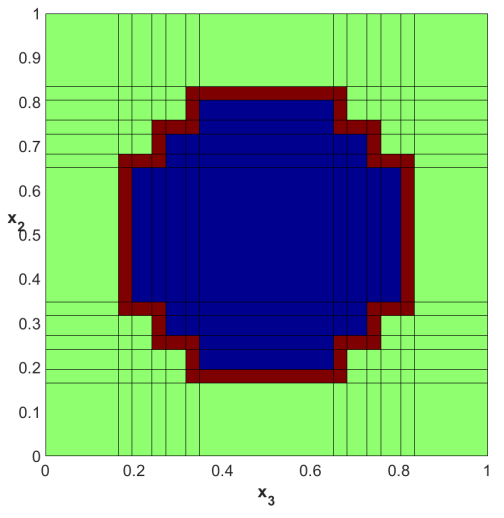

Figure 7: RUC used in stochastic analyses.

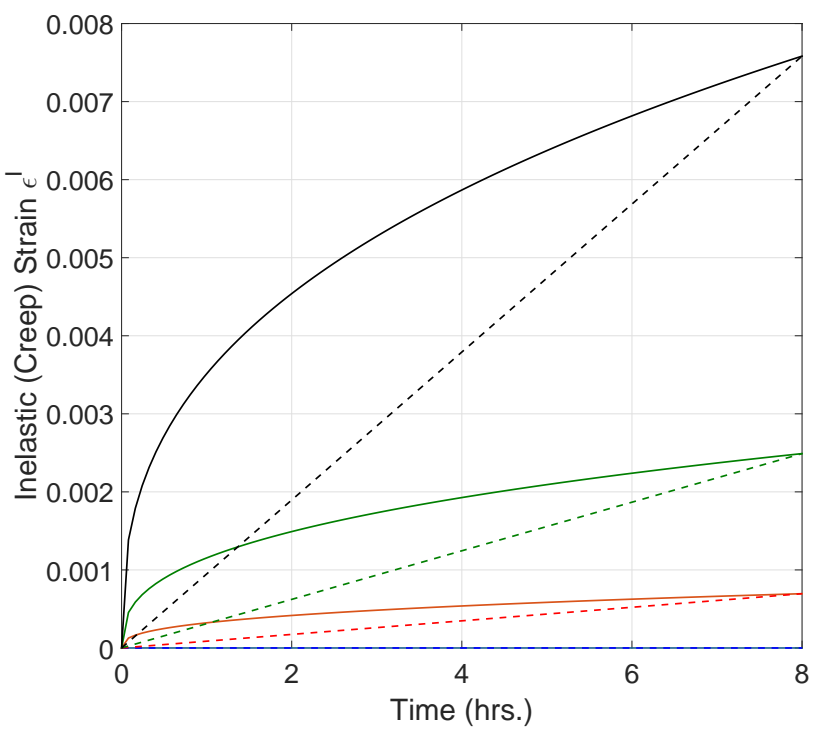

\begin{tabular}{|l}
\hline - RT Primary (DiCarlo and Morscher, 1991) \\
$-\mathrm{T}_{3}$ Primary (DiCarlo and Morscher, 1991) \\
$-\mathrm{T}_{2}$ Primary (DiCarlo and Morscher, 1991) \\
$-\mathrm{T}_{1}$ Primary (DiCarlo and Morscher, 1991) \\
$---\mathrm{RT}$ Steady State Approximation \\
$--\mathrm{T}_{3}$ Steady State Approximation \\
$--\mathrm{T}_{2}$ Steady State Approximation \\
$--\mathrm{T}_{1}$ Steady State Approximation
\end{tabular}

Figure 8: Comparison of primary creep and steady state, power law approximation over processing duration at critical processing temperatures.

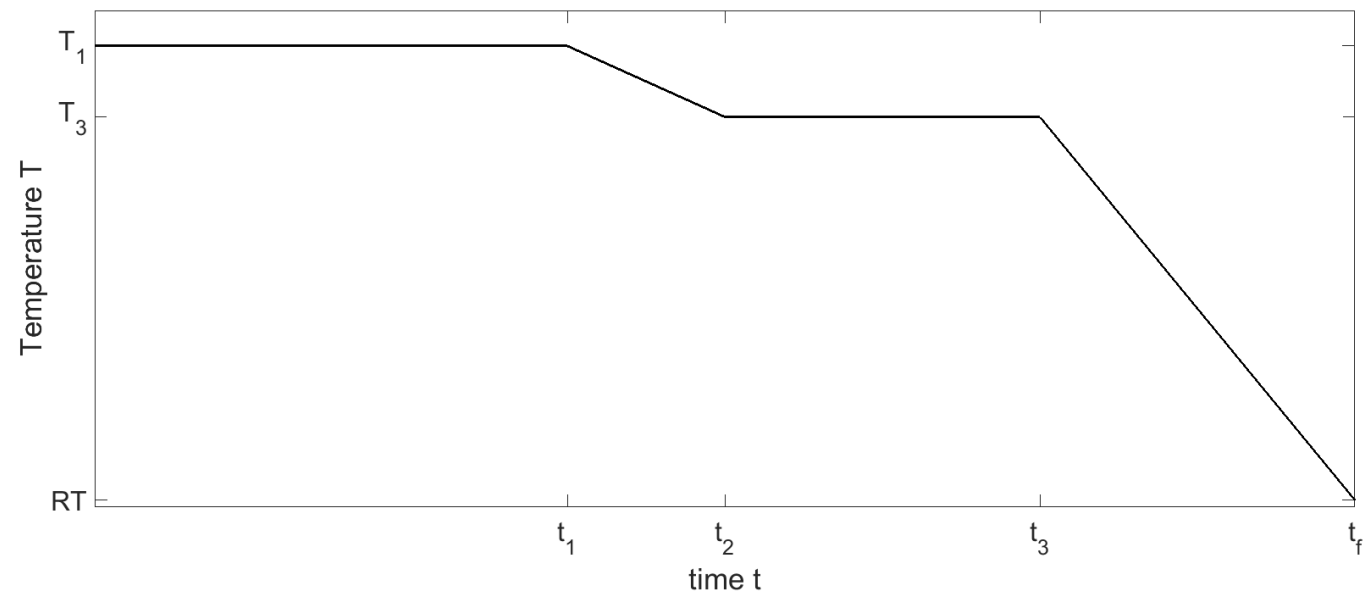

Figure 9: Thermal loading applied to RUC to simulate processing. 

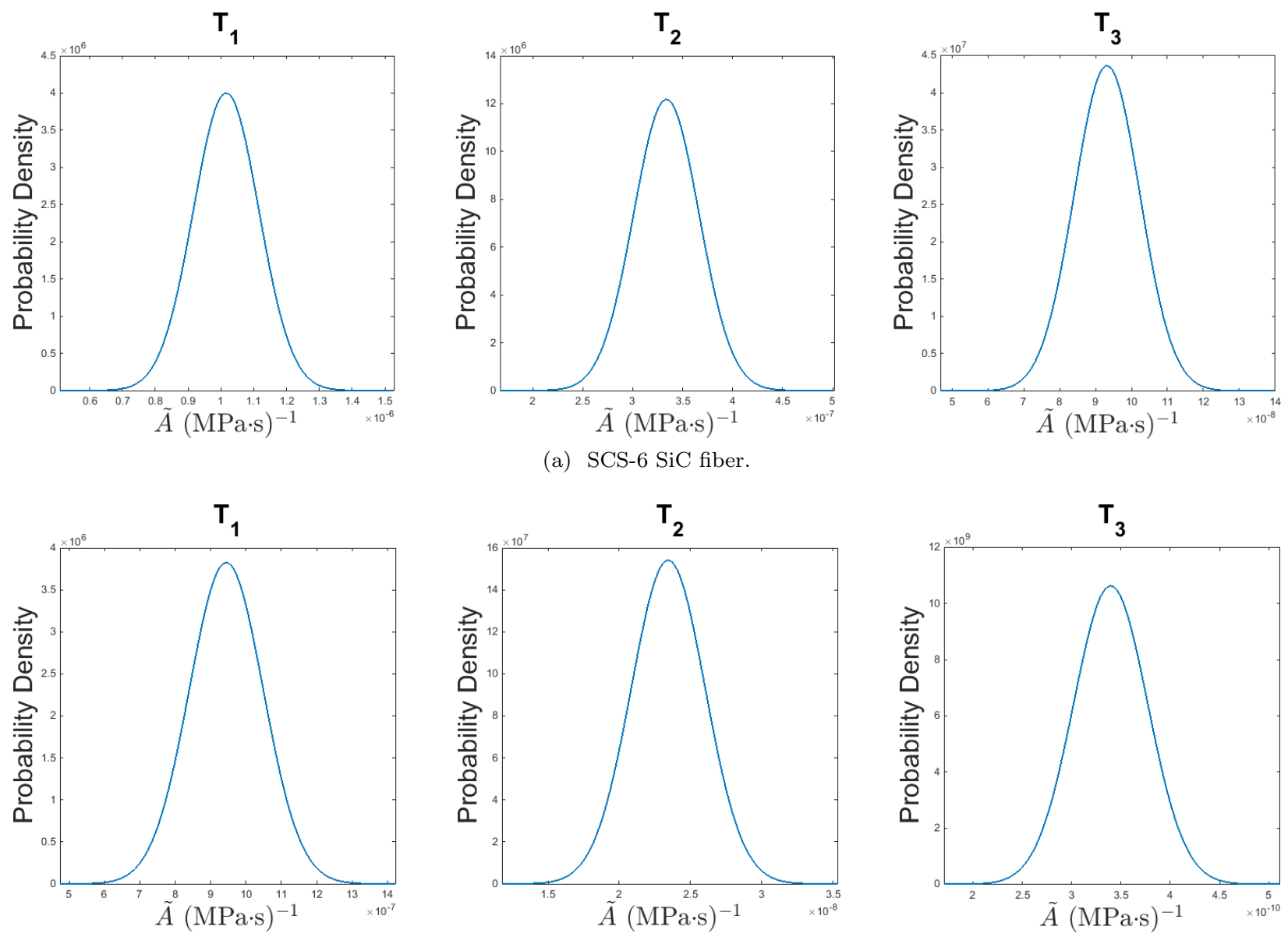

(b) RSBN matrix.

Figure 10: Probability density functions of power law creep parameter $\tilde{A}$ at critical processing temperatures $\left(T_{1}>T_{2}>T_{3}\right)$ for SCS-6 fiber and RSBN matrix.

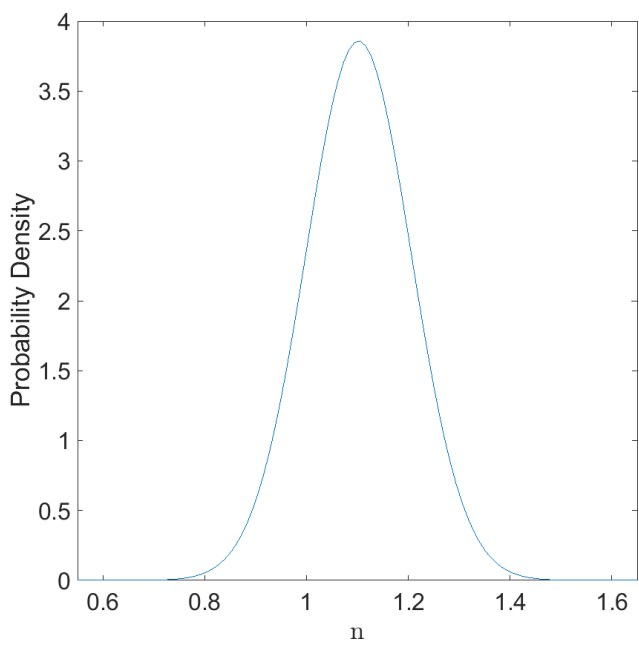

(a) SCS-6 SiC fiber.

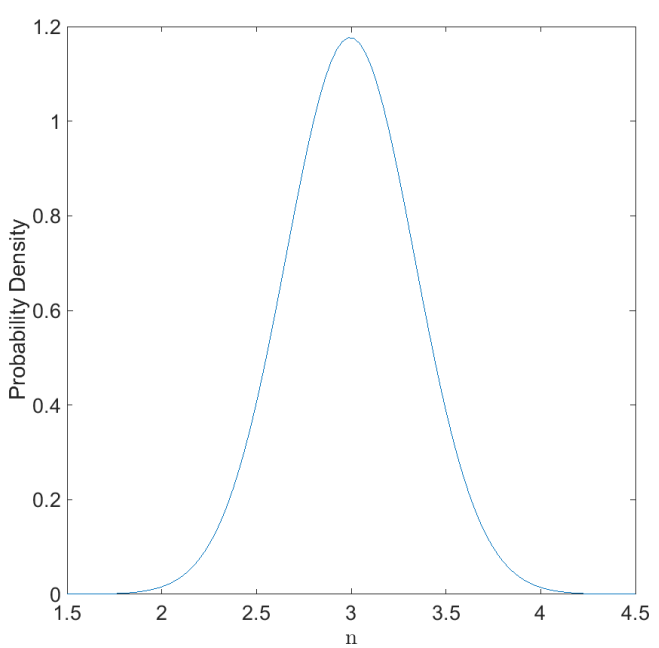

(b) RSBN matrix.

Figure 11: Probability density functions of power law creep parameter $n$ for SCS-6 fiber and RSBN matrix. 


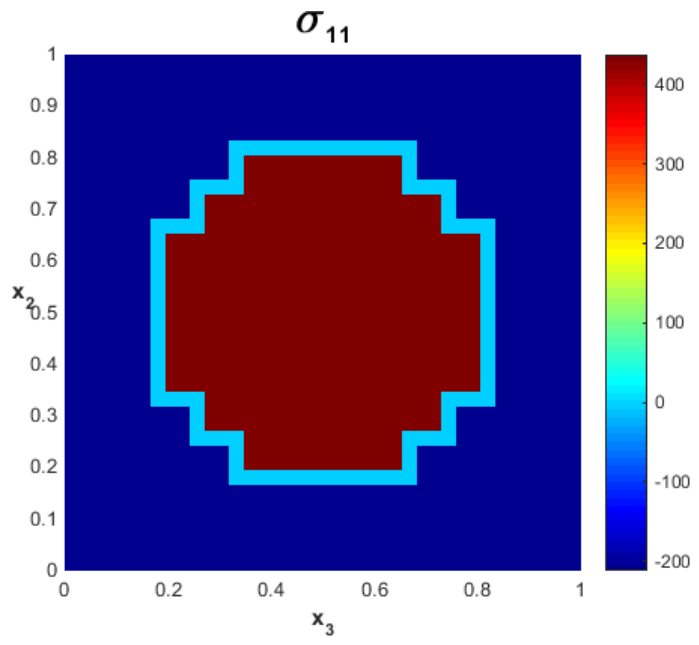

(a) No time-dependent deformation.

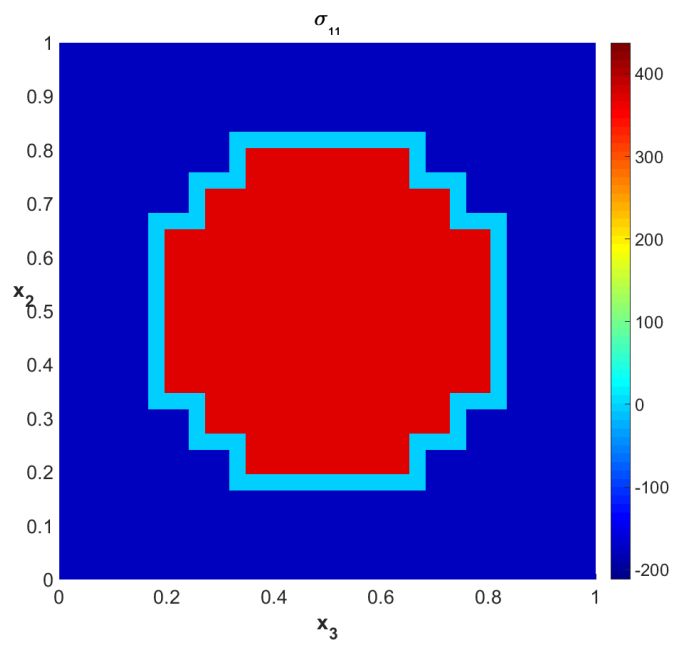

(b) Deterministic time-dependent deformation.

Figure 12: Predicted residual stresses in SiC-RBSN unidirectional RUC after processing with and without time-depndent behavior in the constituents.

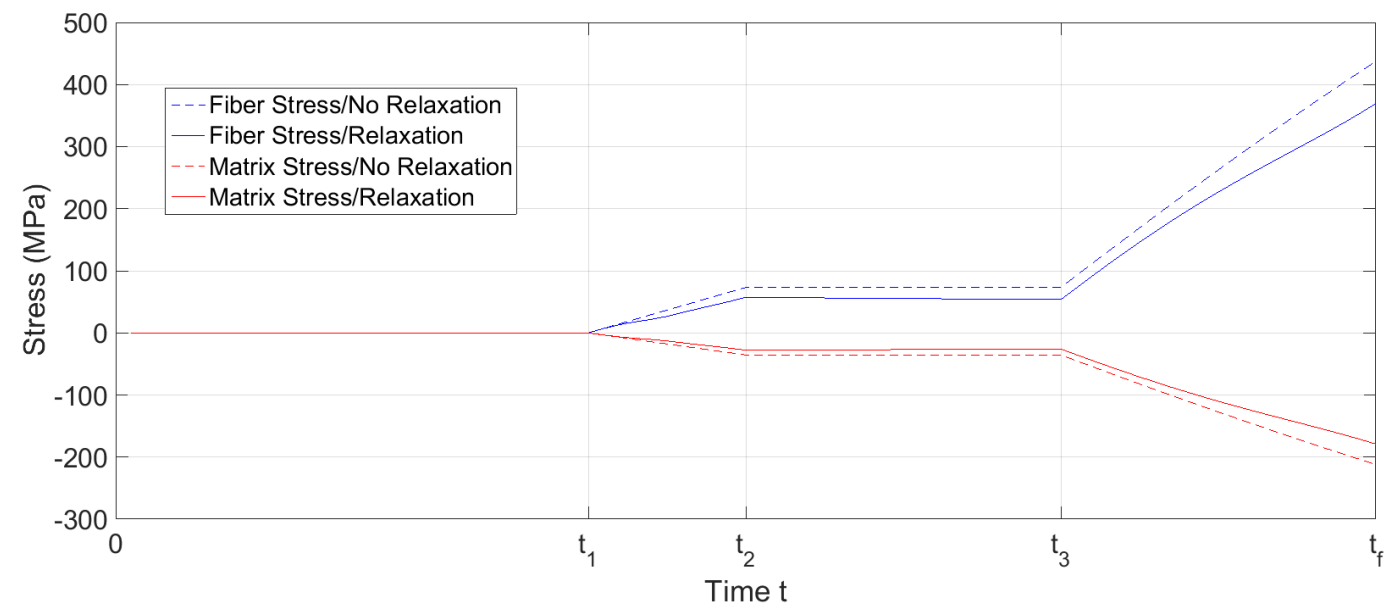

Figure 13: Predicted residual stress history in SCS-6 SiC fiber and RBSN matrix during processing of unidirectional CMC RUC with and without time-dependent behavior in constituents. 

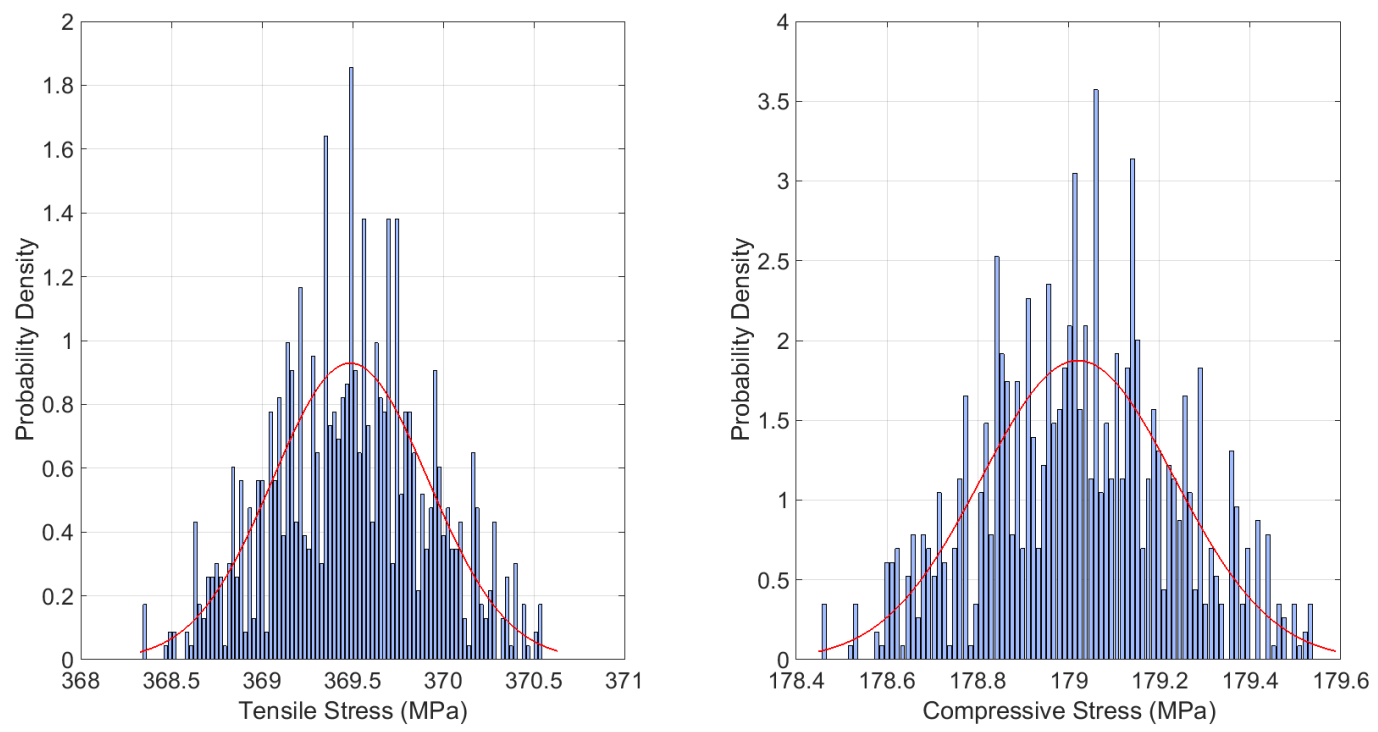

Figure 14: Histogram and PDF of predicted residual stresses after processing in a SiC-RBSN unidirectional RUC assuming a normal distribution in the SCS-6 SiC fiber power law creep parameter $\tilde{A}^{f}$. Left: Maximum Axial Tensile Stress in Fiber, Mean Stress $=369.5 \mathrm{MPa}$, Standard Deviation $=0.43 \mathrm{MPa}$. Right: Maximum Axial Compressive Stress in Matrix, Mean Stress $=179.0 \mathrm{MPa}$, Standard Deviation $=0.21 \mathrm{MPa}$.
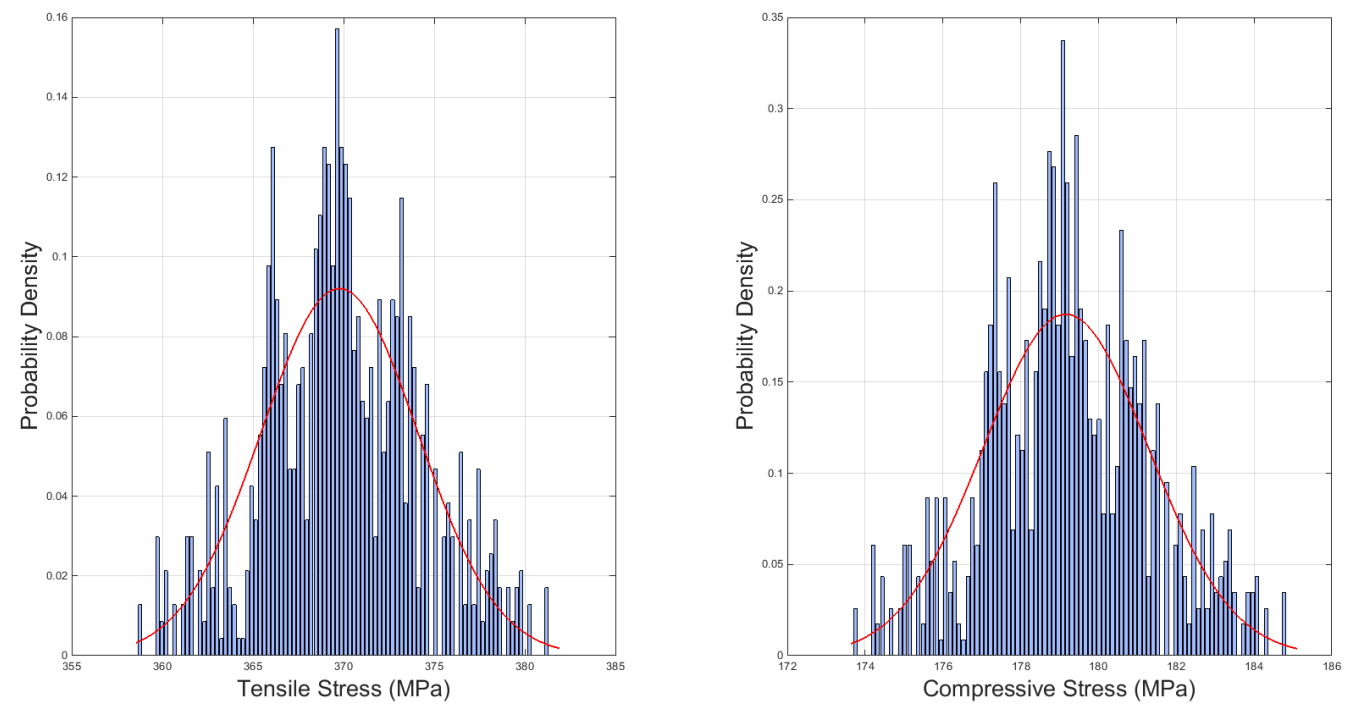

Figure 15: Histogram and PDF of predicted residual stresses after processing in a SiC-RBSN unidirectional RUC assuming a normal distribution in the RBSN matrix power law creep parameter $\tilde{A^{m}}$. Left: Maximum Axial Tensile Stress in Fiber, Mean Stress $=369.8 \mathrm{MPa}$, Standard Deviation $=4.34 \mathrm{MPa}$. Right: Maximum Axial Compressive Stress in Matrix, Mean Stress 179.2 = MPa, Standard Deviation $=2.13 \mathrm{MPa}$. 

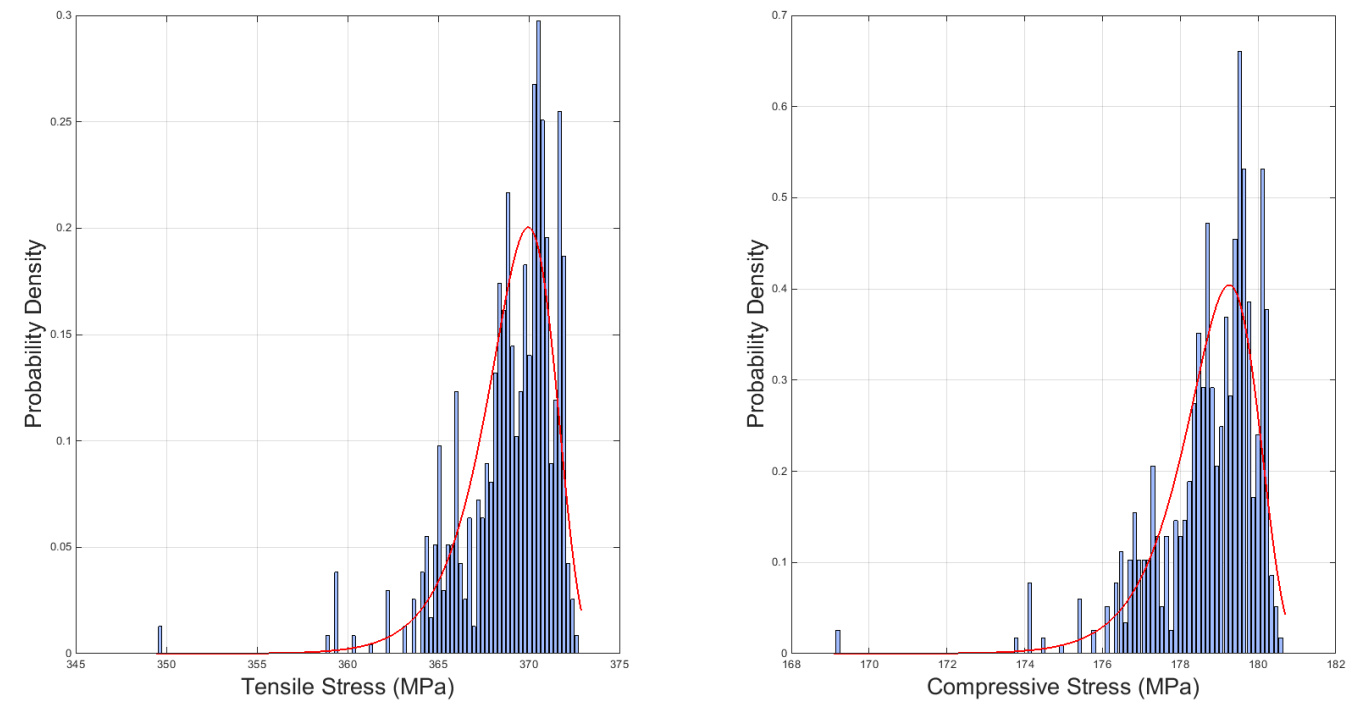

Figure 16: Histogram and PDF of predicted residual stresses after processing in a SiC-RBSN unidirectional RUC assuming a normal distribution in the SCS-6 SiC fiber power law creep parameter $n^{f}$. Left: Maximum Axial Tensile Stress in Fiber, Mean Stress = 369.0 MPa, Standard Deviation = 2.34 MPa. Right: Maximum Axial Compressive Stress in Matrix, Mean Stress $=178.8 \mathrm{MPa}$, Standard Deviation $=1.16 \mathrm{MPa}$.
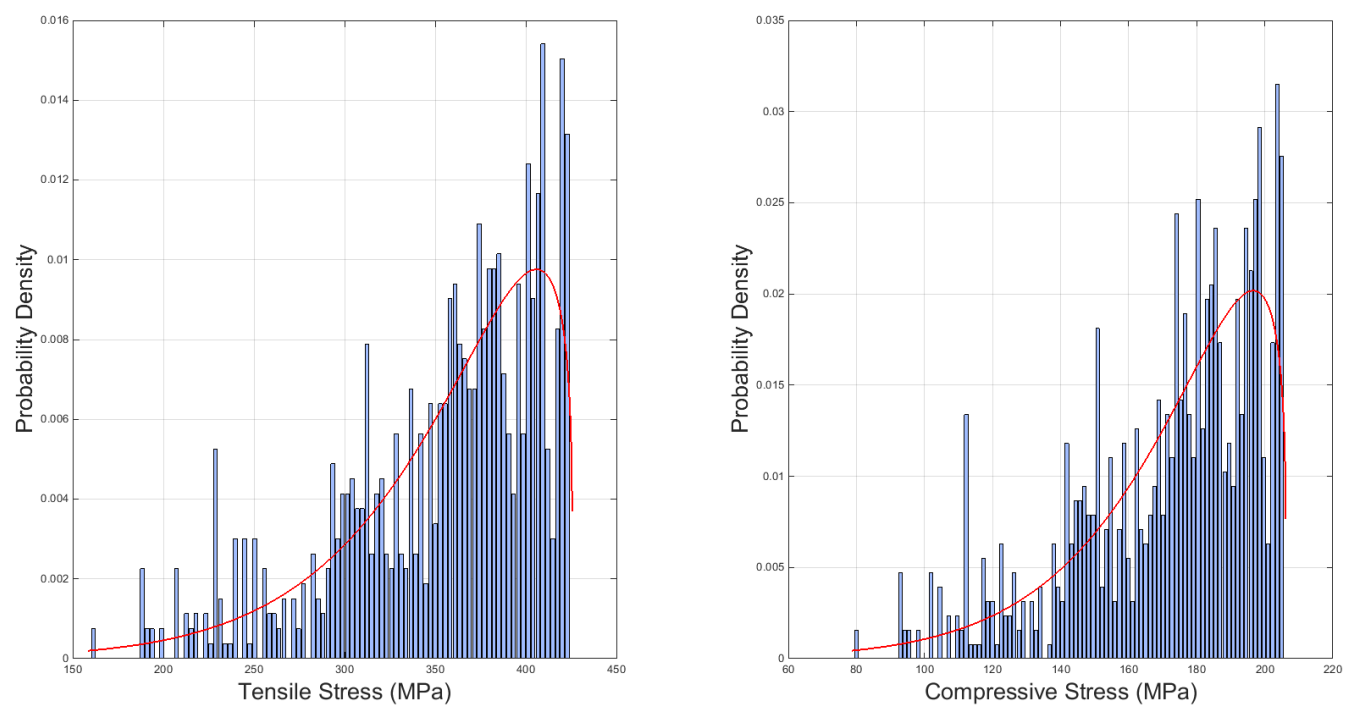

Figure 17: Histogram and PDF of predicted residual stresses after processing in a SiC-RBSN unidirectional RUC assuming a normal distribution in the RBSN matrix power law creep parameter $n^{m}$. Left: Maximum Axial Tensile Stress in Fiber, Mean Stress $=354.4 \mathrm{MPa}$, Standard Deviation = 58.1 MPa. Right: Maximum Axial Compressive Stress in Matrix, Mean Stress $=171.8 \mathrm{MPa}$, Standard Deviation $=28.1 \mathrm{MPa}$. 


\section{References}

${ }^{1}$ Dunn, D. G., The Effect of Fiber Volume Fraction in Hipercomp SiC-SiC Composites, Ph.D. thesis, Alfred University, Alfred, New York, 2010.

${ }^{2}$ Chulya, A., Gykenyesi, J. P., and Bhatt, R. T., "Mechanical behavior offiber reinforced SiC/RBSN ceramic matrix composites: Theory and experiment," NASA/TM 103688, 1991.

${ }^{3}$ Goldberg, R. K., "Utilization of the generalizaed method of cells to analyze the deformation response of laminated ceramic matrix composites," NASA/TM 2012-217737, 2012.

${ }^{4}$ Bednarcyk, B. A., Mital, S. K., Pineda, E. J., and Arnold, S. M., "Multiscale modeling of ceramic matrix composites," $56 t h$ AIAA/ASME/ASCE/AHS/ASC Structrues, Sturctural Dynamics, and Materials Conference, Kissimmee, FL, 5-9, January 2015.

${ }^{5}$ Sullivan, R. W. and Arnold, S. M., "An annotative review of multiscale modeling and its application to scales inherent in the field of ICME," Models, Databases, and Simulation Tools Needed for the Realization of Integrated Computational Materials Engineering: Proceedings of the Symposium Held at Materials Science $\&$ Technology 2010, edited by S. M. Arnold and T. T. Wong, ASM International, Houston, Texas, 2011, pp. 6-23.

${ }^{6}$ Mori, T. and Tanaka, K., "Average stresses in matrix and average energy of materials with misfitting inclusions," Acta Metall., Vol. 21, 1973, pp. 571-574.

${ }^{7}$ Oskay, C. and Fish, J., "Eigendeformation-based reduced order homogenization for failure analysis of heterogeneous materials," Comput. Methods in Appl. Mech. and Eng., Vol. 196, 2007, pp. 1216-1243.

${ }^{8}$ Ghosh, S. and Liu, Y., "Voronoi cell finite element model based on micorpolar theory of thermoelasticity for heteogeneous materials," Int. J. Numer. Methods Eng., Vol. 38, 1995, pp. 1361-1398.

${ }^{9}$ Aboudi, J., Arnold, S. M., and Bednarcyk, B. A., Micromechanics of Composite Materials: A Generalized Multiscale Analysis Approach, Elsevier, Inc., 2013.

${ }^{10}$ Paley, M. and Aboudi, J., "Micromechanical Analysis of Composites by the Generalized Cells Model," Mechanics of Materials, Vol. 14, 1992, pp. 127-139.

${ }^{11}$ Liu, K. C. and Arnold, S. M., "Statistical influence of scale specific features on the progressive damage of woven ceramic matrix composites (CMCs)," CMC-Comput. Mater. Con., Vol. 35, No. 1, 2013, pp. 35-36.

${ }^{12}$ Wilt, T. E., "On the finite element implementation of the generalized method of cells micromechanics constitutive model," Nasa/cr-1995-195451, 1995.

${ }^{13}$ Bednarcyk, B. A. and Arnold, S. M., "A framework for performing multiscale stochastic progressive failure analysis of composite structures," Proceedings of the 2006 ABAQUS User's Conference, 23-25, May 2006.

${ }^{14}$ Gilat, R. and Banks-Sills, L., editors, Advances in Mathematical Modeling and Experimental Methods for Materials and Structures: The Jacob Aboudi Volume, Vol. 168 of Solid Mechanics and Its Applications, Springer, 2010.

${ }^{15}$ Bednarcyk, B. A. and Arnold, S. M., "Framework for pefrominf multiscale stochastic progressive failure analysis of composite structures," NASA/TM 2007-214694, 2007.

${ }^{16}$ Ricks, T. M., Lacy, Jr., T. E., Bednarcyk, B. A., and Arnold, S. M., "A multiscale modeling methodology for metal matrix composites including fiber strength," 53th AIAA/ASME/ASCE/AHS/ASC Structrues, Sturctural Dynamics, and Materials Conference, Honolulu, HI, 23-26, April 2012.

${ }^{17}$ Ricks, T. M., Lacy, Jr., T. E., Pineda, E. J., Bednarcyk, B. A., and Arnold, S. M., "The effect of scale dependent discretization on the progressive failure of composite materials using multiscale analyses," 54th AIAA/ASME/ASCE/AHS/ASC Structrues, Sturctural Dynamics, and Materials Conference, Boston, MA, 8-11, April 2013.

${ }^{18}$ Arnold, S. M., Murthy, P., Bednacryk, B. A., and Pineda, E. J., "Microsructural influence on deformation and fatigue life of composites using the generalized method of cells," 56th AIAA/ASME/ASCE/AHS/ASC Structrues, Sturctural Dynamics, and Materials Conference, Kissimmee, FL, 5-9, January 2015.

${ }^{19}$ Bhatt, R. T. and Phillips, R. E., "Laminate behavior od SiC fiber-reinforced reaction-bonded silicon nitride matrix composites," J. Compos. Tech. Res., Vol. 12, No. 1, 1990, pp. 13-23.

${ }^{20}$ Bhatt, R. T., "Silicon Carbide Fiber-Reinforced Silicon Nitride Composites," Handbook of Ceramic Matrix Composites, edited by N. P. Bansal, Kluwer Academic Publisher, 2005.

${ }^{21}$ Holmes, J. W., Park, Y. H., and Jones, J. W., "Tensile creep and creep-recovery behavior of a $\mathrm{SiC}_{-\mathrm{Fiber}-\mathrm{Si}} \mathrm{N}_{4}-\mathrm{Matrix}$ Composite," J. Am. Ceram. Soc., Vol. 76, No. 5, 1993, pp. 1281-1293.

${ }^{22}$ Cannon, W. R. and Langdon, T. G., "Creep of ceramics. 1. Mechanical characteristics," J. Mater. Sci., Vol. 18, 1983, pp. $1-50$.

${ }^{23}$ Chaung, T. J., "Estimation of power-law creep paramters from bend test data," J. Mater. Sci., Vol. 21, 1986, pp. 165-175.

${ }^{24}$ Bednarcyk, B. A. and Arnold, S. M., "MAC/GMC 4.0 User's Manual - Keywords Manual," NASA/TM 2002212077/VOL2, 2002.

${ }^{25}$ Bednarcyk, B. A. and Arnold, S. M., "MAC/GMC 4.0 User's Manual - Example Problems Manual," NASA/TM 2002212077/VOL3, 2002.

${ }^{26}$ Bednarcyk, B. A., Arnold, S. M., Pineda, E., and Mital, S. K., "Synergistic multiscale modeling of ceramic matrix composites," IUTAM Symposium on Connecting Multiscale Mechanics to Complex Material Design, Evanston, IL, 14-16, May 2014.

${ }^{27}$ DiCarlo, J. A. and Morscher, G. N., "Creep and stress relaxation modeling of polycrystalline ceramic fibers," NASA/TM 105394, 1991.

${ }^{28}$ Lacy, Jr., T. E., McDowell, D. L., and Talreja, R., "Gradient concepts for evolution of damage," Mech. Mater., Vol. 31, 1999, pp. 831-860.

${ }^{29}$ Tracy, J., Waas, A. M., and Daly, S., "Constituent level characterization of damage in ceramic matrix composites at high temperature," J. Am. Ceram. Soc., 2015, Under Review.

${ }^{30}$ Pineda, E. J., Bednarcyk, B. A., Waas, A. M., and Arnold, S. M., "Progressive failure of a unidirectional fiber-reinforced composite using the method of cells: Discretization objective computational results," Int. J. Solids Struct., Vol. 50, No. 9, 2013, pp. 1203-1216. 

